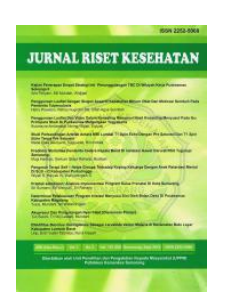

Jurnal Riset Kesehatan, 8 (2), 2019, 33 - 39

DOI: $10.31983 /$ jrk.v8i2.3811

Jurnal Riset Kesehatan

http://ejournal.poltekkes-smg.ac.id/ojs/index.php/jrk

\title{
THE SURVEY OF SAFETY CULTURE IN RSUP Dr. KARIADI SEMARANG
}

\author{
Elyana Sri Sulistyowati ${ }^{\mathrm{a}^{*}}$; Septi Dewi Muninggar ${ }^{\mathrm{b}}$; Verarica Silalahic ${ }^{\mathrm{c}}$; Debi Ariyanto ${ }^{\mathrm{d}}$; \\ Endang Fatmawati ${ }^{\mathrm{e}}$; Dharma Wahyu Edhy ${ }^{\mathrm{f}}$; Anggit Anandoyog \\ a,b,c,d,e,f,g Quality and Patient Safety Committee of RSUP Dr.Kariadi Semarang ; \\ Dr. Sutomo 16, Semarang 50244 ; Indonesia
}

\begin{abstract}
Patient safety in hospitals is a crucial issue as significant medication errors occur in some countries. Patient safety incidence is inevitably related to safety culture implemented in hospitals. This survey aims to investigate the dimension of patient safety serving as a strong area and dimension for potential improvement. This study used a cross-sectional approach involving 361 subjects in all units in RSUP Dr. Kariadi. Findings are presented in graphs and frequency tables. This study found three dimensions of strength area involving management support regarding patient safety $(92.93 \%)$, organizational learning-continuous improvement $(91.73 \%)$, and unit cooperation $(86.1 \%)$. Meanwhile, the area for potential improvement involving employment (45.43\%), incidence report frequency $(58.07 \%)$, and open communication (60.67\%). Dimensions serving as strength areas need to be maintained while dimension for potential improvement need for support to cultivate patient safety culture in RSUP Dr. Kariadi.
\end{abstract}

Keywords: survey ; patient safety culture ; patient safety dimensions ; strength area ; area for potential improvement

\section{Introduction}

The hospital provides complex and risky health services. In hospitals, there are hundreds of medicines, laboratory tests, and procedures, highly sophisticated medical equipment, diverse medics, and non-medics providing 24 hours services. Undesired incidence and near-missed incidence may occur when service diversity and routinely are poorly managed. (Health Ministry, 2008).

One of the quality indicators in hospital accreditation is based on the International Patient Safety Goal (IPSG) referring to the standard of the Joint Commission International (JCI) (Health Ministry, 2011). There are five crucial issues related to safety in hospitals involving patient safety, employee or health professional safety,

\footnotetext{
*) Corresponding Author (Elyana Sri Sulistyowati)

Email: elyana.ss@gmail.com
}

building and facility safety affecting patient and employee or health professional safety, environment safety (green productivity) affecting environment contamination and hospital business safety pertinent with business continuity (Health Ministry, 2010).

Patient safety in hospitals is a crucial issue since a significant number of medical errors occur in some countries. The World Health Organization reported incidences of patient safety in which medical errors experienced by $8-12 \%$ of inpatients while $23 \%$ of European people experienced serious medical errors in hospitals and $11 \%$ of them reported having been prescribed wrong medicines (WHO, 2016).

Fifty percent of death associated with medical injuries are preventable (Cahyono and Suhardjo, 2012). The Institute of Medicines (IOM) in 2000 in America published a paper "To Err is Human, Building to Safer Health System" 
reporting that $2.9 \%$ and $6.6 \%$ of adverse events in Utah and Colorado hospitals respectively lead to death while $3.7 \%$ of adverse events occurred in New York resulting in death in $13.7 \%$ of them. Death rate related to adverse events among 33.6 million inpatients in American was about 44 thousand up to 98 thousand people per annum (Budiharjo, 2008).

The Quality in Australian Health Care Study (QAHC) found that 2,353 of 14,179 patients experience adverse events. In the United Kingdom (UK), it was found that 119 adverse events of 1,014 patients in 1999-2000 (Health Ministry, 2008). Based on patient safety incidence report, adverse events in Indonesia in 2007 and 2010 were about $46.2 \%$ and $6.3 \%$ respectively (Lumenta, 2008). In 2009, 2010 and 2011, it was reported 114, 103 and 34 cases of patient safety incidences respectively (KKPRS, 2012). Since this data is considered incomplete and less accurate, the number of adverse events was assumed much bigger (KKPRS, 2008). The occurring incidence is inevitably related to safety culture implemented in hospitals. Patient safety culture is a complicated working series involving various dimensions viewing patient safety behavior. Based on the Agency of Healthcare Research and Quality (AHRQ), patient safety culture consists of values, beliefs, and norms of important aspects within organizations and behavior related to patient safety supported, appreciated and desired. It is very crucial in health services to improve patient safety culture to enhance patient safety in health service processes (Chen and Li, 2010).

RSUP Dr. Kariadi has surveyed patient safety culture since 2006 up to now. The findings show that the dimension of hand over and transition is about $43 \%$, around $41 \%$ issues often arise during information exchange between units within hospital, around $42 \%$ of issues related to missed important information pertinent with patient services during hand over, reported incidence was about $43 \%$, non judgemental culture was about $53 \%$, and $30 \%$ staffs concern their mistakes will be recorded in their personnel files. A survey of patient safety culture in 2017 show that of 12 patient safety dimensions, condition with potential improvement involving response aspect without punishment for about $30 \%$, workforce aspect for about $52 \%$, and communication aspect and feedback pertinent with patient safety for about $57 \%$.

This survey aims to describe patient safety culture in RSUP Dr. Kariadi in 2018 to identify strength areas and areas for potential improvement.

\section{Method}

This study is a quantitative survey with a cross-sectional approach to describe patient safety culture in RSUP Dr. Kariadi Semarang in 2018. This study was conducted between May $1^{\text {st }}$ and December $31^{\text {st }}, 2018$ from proposal writing until the dissemination of research findings. This study is part of an annual survey conducted by the quality and patient safety committee to identify patient safety culture per year.

The population of this survey is all employees of RSUP Dr. Kariadi Semarang. The sample involved 361 subjects. The sampling technique was proportionate stratified random sampling based on available working units. Inclusion criteria involve 1) employees of RSUP Dr. Kariadi, 2) who already have patient safety training, and 3) give consent to be a research subject. The exclusion criteria involve employees 1) who are taking leave or sickness absence.

This study involves a single variable patient safety culture in RSUP Dr. Kariadi hospital Semarang. It employed a questionnaire Hospital Survey on Patient Safety Culture (HSOPSC) from the Agency for Healthcare Research \& Quality translated into Indonesian. The findings were presented in a univariate form, the description of frequency distribution and diagram based on respondent characteristics, 12 dimensions of patient safety and potential improvement.

\section{Result and Discussion}

Subject characteristics show respondents based on working years in hospital, working years in units, working hours per week, positions, direct contact with patients, and working years of current profession. Some prominent characteristics involve working years in hospital $(33.5 \%)$, working years in unit between 1 and 5 years $(50.9 \%)$, working hours per week $\geq 40$ hours $(79.2 \%)$, nurse $(40.3 \%)$, direct contact with patients $(68.0 \%)$, and working years of current profession between 1 and 5 years (33.6\%). 
Table 1. Subject Characteristics

\begin{tabular}{|c|c|c|c|}
\hline Characteristic & $\mathrm{f}$ & $\%$ & $\%$ Valid \\
\hline \multicolumn{4}{|l|}{ Working years in hospital } \\
\hline$-<1$ year & 29 & 8.0 & 8.3 \\
\hline - 1-5 years & 117 & 32.4 & 33.5 \\
\hline - 6-10 years & 74 & 20.5 & 21.2 \\
\hline - $11-15$ years & 33 & 9.1 & 9.5 \\
\hline - 16-20 years & 35 & 9.7 & 10.0 \\
\hline$-\geqslant 21$ years & 61 & 16.9 & 17.5 \\
\hline Total & 349 & 96.7 & 100.0 \\
\hline Do not answer & 12 & 3.3 & \\
\hline \multicolumn{4}{|l|}{ Working years in units } \\
\hline$-<1$ year & 44 & 12.2 & 12.6 \\
\hline - $1-5$ years & 177 & 49.0 & 50.9 \\
\hline - 6-10 years & 62 & 17.2 & 17.8 \\
\hline - 11-15 years & 25 & 6.9 & 7.2 \\
\hline - 16-20 years & 17 & 4.7 & 4.9 \\
\hline$-\geqslant 21$ years & 23 & 6.4 & 6.6 \\
\hline Total & 348 & 96.4 & 100.0 \\
\hline Do not answer & 13 & 3.6 & \\
\hline \multicolumn{4}{|l|}{ Working hours per week } \\
\hline - $<20$ hours per week & 6 & 1.7 & 1.7 \\
\hline - 20-39 hours per week & 66 & 18.3 & 19.1 \\
\hline$-\geqslant 40$ hours per week & 274 & 75.9 & 79.2 \\
\hline Total & 346 & 95.8 & 100.0 \\
\hline Do not answer & 15 & 4.2 & \\
\hline \multicolumn{4}{|l|}{ Positions } \\
\hline - Physician & 17 & 4.7 & 4.9 \\
\hline - Physiotherapist & 1 & 0.3 & 0.3 \\
\hline - Nurse & 141 & 39.1 & 40.3 \\
\hline - Laboratory analyst & 9 & 2.5 & 2.6 \\
\hline - Pharmacist & 9 & 2.5 & 2.6 \\
\hline - Sanitarian & 2 & 0.6 & 0.6 \\
\hline - Pharmacist assistant & 9 & 2.5 & 2.6 \\
\hline - Technician & 9 & 2.5 & 2.6 \\
\hline - Dietician & 10 & 2.8 & 2.9 \\
\hline - Radiographer & 6 & 1.7 & 1.7 \\
\hline - Administrative officer & 42 & 11.6 & 12.0 \\
\hline - Security & 20 & 5.5 & 5.7 \\
\hline - Others & 75 & 20.8 & 21.4 \\
\hline Total & 350 & 97.0 & 100.0 \\
\hline Do not answer & 11 & 3.0 & \\
\hline \multicolumn{4}{|l|}{ Direct contact with patients } \\
\hline - Yes & 240 & 66.5 & 68.0 \\
\hline - No & 113 & 31.3 & 32.0 \\
\hline
\end{tabular}

\begin{tabular}{lrrr}
\hline \multicolumn{1}{c}{ Characteristic } & $\mathrm{f}$ & $\%$ & $\%$ Valid \\
\hline Total & 353 & 97.8 & 100.0 \\
& & & \\
\hline Do not answer & 8 & 2.2 & \\
& & & \\
\hline Working years of current & & & \\
profession & 29 & 8.0 & 8.3 \\
- <1 year & 117 & 32.4 & 33.6 \\
- 1-5 year & 80 & 22.2 & 23.0 \\
- 6-10 year & 37 & 10.2 & 10.6 \\
- 11-15 year & 37 & 10.2 & 10.6 \\
- 16-20 year & 48 & 13.3 & 13.8 \\
- $\geqslant 21$ year & & & \\
\hline Total & 348 & 96.4 & 100.0 \\
& & & \\
\hline Do not answer & 13 & 3.6 & \\
& & & \\
\hline
\end{tabular}

\section{The Dimension of Patient Safety}

The survey found that three dimensions with high positive responses are management support for patient safety (92.93\%), organizational learning-continuous improvement $(91.73 \%)$, and cooperation across units $(86.1 \%)$. Dimensions with low positive responses are employment (45.43), incidence report frequency $(58.07 \%)$ and open communication $(60.67 \%)$.

Safety culture needs an understanding of the importance of value, belief, and norm for the hospital, also attitude and behavior related to desired patient safety. Creating and maintaining safety culture is a challenge and should be a sustainable attempt since health organizations are a risky place for those receiving and providing care (Wagner, 2014).

RSUP Dr. Kariadi is a health organization conducting a culture survey since 2016. Patient safety culture trend shows each dimension involving strength area and area with a potential improvement. Three dimensions with a high score are postulated as strength areas while three dimensions with low scores are postulated as the area with a potential improvement. However, these dimensions have a positive response during a survey in Roemani hospital (67.6\%) (Ultaria et al., 2017).

Safety culture is not isolated from components of decision-maker level and management level commitment. These components are the foundation within organization and management hierarchical 
responsibilities (Cahyono dan Suhardjo, 2012; IAEA, 1991). Within these dimensions, questions having the highest positive response (98\%) is item F8 "the action of hospital management showing that patient safety is the prime priority." This is in line with the main function of RSUP Dr. Kariadi focusing on and prioritizing patient safety in every health service.

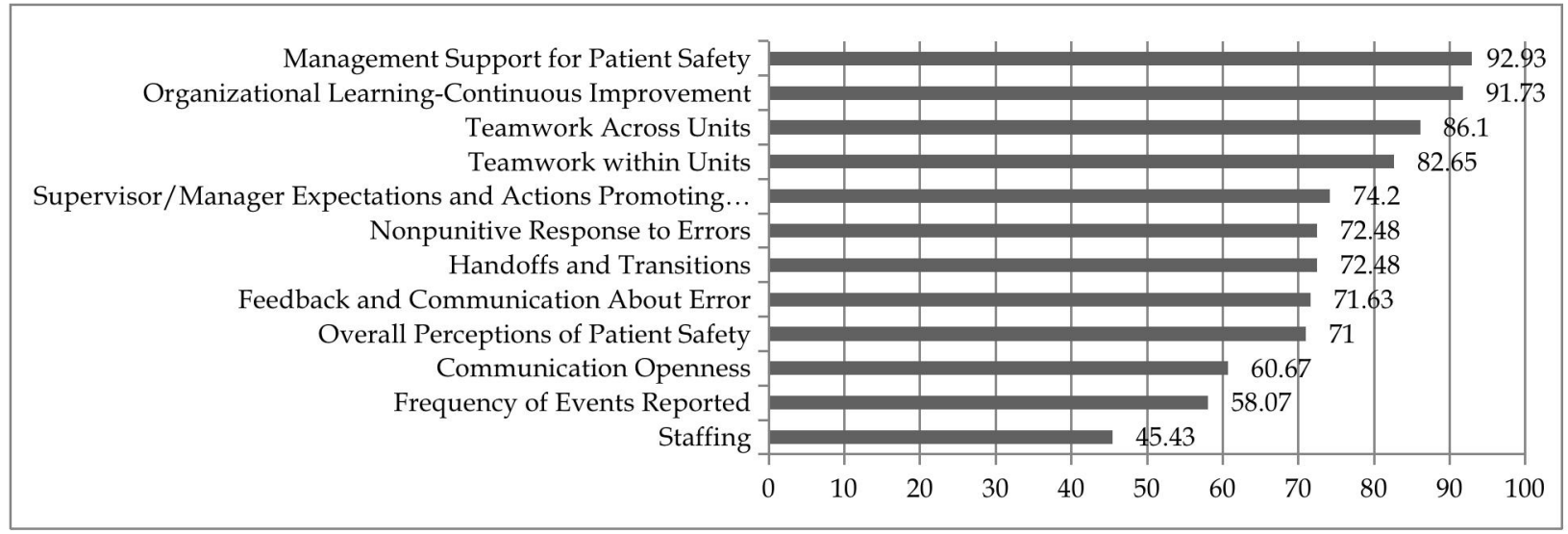

Figure 1. Positive Response to Patient Safety Dimension the dimension of management support toward patient safety in RSUP Dr. Kariadi in 2018 is one of the strongest areas, organizational learning continuous improvement dimension also synergize creating strength area for creating a patient safety culture.

\section{Organizational Learning - Continous}

\section{Improvement}

This dimension has become a strength area with a positive response in 2016, 2017 and 2018 for about $84 \%$, 98\%, and $91.73 \%$ respectively. These findings are in line with a survey conducted by Jia et al. (2014) taking place in Chinese hospitals. They found that organizational learning - continuous improvement becomes a dimension with the highest positive response among other dimensions (88\%). Galvao et al. (2018) also found similar results in which this response is among other dimensions with the highest positive response (58\%). Similarly, Alharbi et al. (2018) state that this dimension yielded around $65.3 \%$ positive response. A meta-analysis (Okuyama et al., 2018) found that this dimension becomes the second-highest dimension (70\%).

Organizational learning - continuous improvement serves as a dimension shaping patient safety culture when people are willing to learn from their mistakes and can improve their potential and capacity (Sammer et al., 2009). Through organizational learning, organizational

Organizational learning and organizational capacity development by management can bring organizations toward better changes (Robbins and Timoty, 2015). Along with study findings,

\section{Cooperation Across Units}

In 2016, this dimension was not included in the strength area (positive response was 70\%) and in 2017 and 2018, this dimension was included as one of the strength area (positive response $83 \%$ and $86.1 \%$ respectively). The positive response trend of this dimension for three consecutive years is increasing. This dimension has a positive trend for three consecutive years. This dimension is in line with that found by Ultaria et al. (2017). Who found a dimension of cooperation between units as a dimension with a strong culture (positive response $80.2 \%$ ).

Hospital is a health provider demanding cooperation from each unit. Cooperation between teams within the hospital serves as a proof of success in delivering medical services to patients even when not each unit is involved in indirect contact with patients. However, with a high positive response within this dimension, it will create a friendly and strong work environment within the hospital, particularly in RSUP Dr. Kariadi.

\section{Area for Potential Improvement}

Dimensions with an area for potential improvement involve staffing, frequency of 
events reported and communication openness.

\section{Staffing}

In 2016, this dimension was not included in the area for potential improvement (positive response 57\%). From 2017, this dimension was included in the area for potential improvement (positive response 52\%) until 2018 (positive response $45.43 \%$ ). Positive response toward this dimension was decreasing over years identified from the question in item A5 "employees in our unit work longer for patient care $(22.1 \%)$. This item is in line with working hours of health professionals per week which is mostly $\geq 40$ hours $(75.9 \%)$ (Table 1). Based on Act No. 13/2003 about employment and workload have been regulated in verse 1 article 77-85, employees work for 7 hours per day or 40 hours per week for 6 working days and 8 hours per day or 40 hours per week for 5 working days. The comparison between survey findings and this act shows that the working hours of employees in RSUP Dr. Kariadi have exceeded the working hours regulated by the act. Overtime can lead to absenteeism. In turn, absenteeism is related to patient safety culture (Brborović and Brborović, 2017).

Similar findings are found in China and Saudi Arabia showing that employment dimension has the lowest positive response in China (45\%) (Jia et al., 2014), Saudi Arabia (Alwabel et al., 2015) and Brazil (Galvao et al., 2018) (33\%). A meta-analysis (Okuyama et al., 2018) shows that the employment dimension is one of three factors with the lowest positive response $(36 \%)$. Meanwhile, the employment dimension has become a strength area in Japan (Hirose et al., 2013).

The patient safety culture should start with health professionals. With a high workload, professionals may experience an amygdala hijack phenomenon, a condition where strong emotions, anxiety, anger, joy or betrayal will leave the amygdala and destroy working memory of the prefrontal cortex. When strong emotion rules over rationality, people can experience sadness or stress so they are unable to think clearly. This phenomenon can be the cause of patient safety incidence (Duffy, 2017).

\section{Frequency of Event Reported}

In 2016, this dimension was identified within an area for potential improvement (positive response 43\%), and in 2017, this dimension was no longer within this area (positive response 67\%). In 2018, this dimension returned to this area (positive response 58.07\%). Based on reported incidence rate, positive response decreased in 2018 in comparison with that in 2017 (61.2\% vs 67\%) even though there was an increase compared with that in 2016 (42\%).

The most frequent incidence report category is no report within the last year for about $38.8 \%$ while the most frequent report category is 1-2 reports $(19.7 \%)$. In contrast with the safety culture survey in RSUP Dr. Kariadi in 2018, a research conducted by Alharbi et al. (2018) placed this dimension as a strength with positive response $62.4 \%$.

Patient safety incidence report frequency is related to understanding and awareness of health professionals, report system and report easiness of any patient safety incidence. Understanding of safety program is much better, but without awareness during its implementation, the patient safety program will not run well including in the form of incidence report. Report system and report easiness should not be a barrier to implementing a patient safety program. No blaming culture is part of the system and easiness for professionals to implement incidence report culture (Vellyana and Rahmawati, 2016).

The survey findings in RSUP Dr. Kariadi in 2018 show a significant increase in the dimension of no blaming culture from the previous year $(72,48 \%$ vs $30 \%)$, but it can not improve averaged dimension of incidence report frequency in 2018. Viewed from statement item of no blaming culture, an item with the lowest positive response is statement item A16 "Employees concern their mistakes will be filed in their performance evaluation" for about $21 \%$. Statement item A16 is tightly related to incidence report frequency. In comparison with the other two statement items of no blaming culture dimension, A12, and A18, statement item A16 is more subjective so become a barrier in improving incidence report frequency. This finding is similar to what was found in qualitative research conducted by Iskandar et al. (2014).

The way of viewing mistakes, fear towards punishment, behavior, response towards adverse events and reporting of adverse events is a culture within the hospital that can impede patient safety program (Cahyono and Suhardjo, 2012). Besides, the unavailability of socialization 
of patient safety incidence analysis findings can impede the implementation of patient safety incidence programs (Vellyana and Rahmawati, 2016). It should be improved over time for the creation of patient safety incident report culture and reward is needed for those reporting incidences.

\section{Communication Openness}

In 2016 and 2017, this dimension was not within the area for potential improvement (positive response 55\% and 77\%). But in 2018, this dimension was included in the area for potential improvement (positive response $60.67 \%$ ). It is similar to what was found by other researchers such as Wei et al. (2015) who found that open communication dimension has a low positive response (54\%). One of the causes is low mentoring towards safety culture. Nurmalia et al. (2013) in their research found that a group with mentoring program intervention experienced a significant improvement of open communication in comparison with the control group. Furthermore, the mentoring program can improve patient safety culture around $20 \%$ in the intervention group.

Open communication is one of the important components in implementing patient safety culture since it is related to mutual trust based on mutual understanding, comfort and safe feeling. Open communication can shape the self-confidence of employees so they can behave better without the feeling of being blamed or judged for mistakes they have made (Ali and Panther, 2008). This concept needs to be implemented to promote patient safety culture, particularly to promote open communication dimension.

\section{Conclusion and Suggestion}

The dimensions serving as a strength area involve management support for patient safety $(92.93 \%)$, organizational learning - continuous improvement $(91.73 \%)$ and teamwork across units $(86.1 \%)$. The dimension serving as an area for potential improvement is staffing (45.43\%), frequency of event reported $(58.07 \%)$ and communication openness (60.67\%).

\section{Acknowledgements}

Special thanks to RSUP Dr. Kariadi Semarang which already funded this safety culture survey until the completion of the survey activities. Thanks to all parties already helped during the process of this survey until its completion.

\section{References}

Agency for Health Care Research and Quality. (2004). Hospital Survey on Patient Survey Culture. Agency for Health Care Research and Quality, 1-5.

Alharbi, W., Cleland, J., and Morrison, Z. (2018). Assessment of Patient Safety Culture in an Adult Oncology Department in Saudi Arabia. Oman Medical Journal, 33(3), 200-208.

Alimohammadzadeh, K., Joladi, S.E., Olya, M., Ghaiyoomi, A., and Arani, H.Z. (2017). A Comparative Study on Effective Factors in Patient Safety Culture from the Nursing Staff Points of View. J. Health Man and Info., 4(2), 57-61.

Ali, P. A., and Panther, W. (2008). Professional Development and the Role of Mentorship. Journal of NursingStandard, 22(42), 35-39.

Alwabel, A.M., Bawazir, A.A., and Al-Surimi, K. (2015). Assessment of Patient Safety Culture Among Pharmacists in Riyadh Hospitals

Saudi Arabia. Journal of Infection and Public Health, 8(4), 402.

Brborović, H., dan Brborović, O. (2017). Patient Safety Culture Shapes Presenteeism and Absenteeism: A Cross-Sectional Study among Croatian Healthcare Workers. Arh Hig Rada Toksikol, 68,185-189.

Budihardjo, A. (2008). The importance of Safety Culture in Hospitals: An attempt to minimize Adverse Events. Integritas-Jurnal Manajemen Bisnis, 1(1), 53-70.

Cahyono, J.B., and Suhardjo, B. (2012). Building Patient Safety Culture in Medical Practice. Yogyakarta: Kanisius.

Chen, I-Chi and Li, Hung-Hui. (2010). Measuring Patient Safety Culture in Taiwan Using the Hospital Survey on Patient Safety Culture (HSOPSC). BMC Health Service Research, 10,152 .

Duffy, W. (2017). Improving Patient Safety by Practicing in a Just Culture. AORN Journal, 106(1), 66-68. 
Galvao, T.F., Lopes, M.C.C., Olivia, C.C.C., Araujo, M.E.A., and Silva, M.T. (2018). Patient Safety Culture in a University Hospital. RLAE, 26, e3014.

Hirose, M., Egami, K., Tsudaya, Y., Honda, J., and Shima, H. A. (2013). Nationwide Survey on Patient Safety Culture in Japan. Value in Health, 16, A680.

IAEA. (1991). Safety culture. Safety Report 75-INSAG-4.

Iskandar, H., Maksum, H., and Nafsiah. (2014). Causing Factors of Decreased Patient Safety Incidence Report in Hospitals. Jurnal Kedokteran Brawijaya, (28(1), 72-77.

Jia, P., Zhang, L., Mao, X., and Zhang, M. (2014). Fostering Patient Safety Culture in Hospital to Improve Health Service: Hospital Survey on Patient Safety Culture. Value in Health, 17, A796.

Health Ministry of Republic of Indonesia. (2008). National Guidelines for Patient Safety in Hospitals. Jakarta.

Health Ministry of Republic of Indonesia. (2010). Strategic Plan of Health Ministry 2010-2014. Jakarta.

Health Ministry of Republic of Indonesia. (2011). Hospital Accreditation Standard, Cooperation between Directorate General of Health Care Promotion of Health Ministry of Republic of Indonesia and the Commission of Hospital Accreditation(KARS). Jakarta.

Hospital Safety committee (KKP-RS) PERSI. (2008). Guidelines of Patient Safety Incidence Report (IKP). Jakarta.

Hospital Safety committee (KKP-RS) PERSI. (2012). Guidelines of Patient Safety Incidence Report. Jakarta.

Lumenta A. (2008). Guidelines of Patient Safety Incidence Report: Patient Safety Incident Report. Jakarta: Hospital Patient Safety Committee KKP-RS.

Nurmalia, D., Handiyani, H., and Pujasari, H.
(2013). The Effect of Mentoring Program towards the Implementation of Patient Safety Culture. Jurnal Manajemen Keperawatan, 1(2), 79-88.

Okuyama, J.H.H., Galvao, T.F., and Silva, M.T. (2018). Healthcare Professional's Perception of Patient Safety Measured by the Hospital Survey on Patient Safety Culture: A Systematic Review and Meta-Analysis. The Scientific World Journal, 1, 1-11.

Pujilestari, A., Maidin, A., and Anggraeni, R. (2014).Patient Safety Cultureiln Inpatient Installation of RSUP Dr. Wahidin Sudirohusodo. Jurnal MKMI, 57-64.

Robbins, S., and Timoty, J. (2015). Organizational Behavior. Jakarta: Salemba Empat.

Sammer, E. C., Lykens, K., Singh, K.P., Mains, D.A., and Lackan, N.A. (2009). What is Patient Safety Culture? A Review Literature. Journal NursingScholarship, 42(2), 156.

Ultaria, T.D., Arso, S.P., and Sriatmi, A. (2017). Description of Patient Safety Culture in Roemani Muhammaddiyah Hospital Semarang. Jurnal Kesehatan Masyarakat, 5(1), 118-125.

Act No. 3 Regulating Workforces. (2003). Jakarta. Vellyana, D., and Rahmawati, A. (2016). Blaming Culture and Mistake Publishment in Patient Safety Culture. Jurnal Ilmiah Kesehatan, 5(9), 600-613.

Wagner, V.D. (2014). Patient Safety : A Cultural Affair. AORN Journal, 100(4), 355-357.

Wei, E., Bassin, B., Santen, S., Sharp, B., Hopson, L., Somand, D., and Fischer, J. (2015). Patient Safety Culture in the Emergency Department. Annals of Emergency Medicine, 66(4s), S51-S52.

World Health Organization. (2018). Patient Safety, About Us. http:/ / www.who.int/patient safety/about/en/index.html [accessed 30 th April 2018]. 